\title{
METABOLIC SYNDROME AND ITS COMPONENTS IN PATIENTS WITH ACUTE CORONARY SYNDROME AT BPKIHS, A TERTIARY CARE CENTER IN NEPAL
}

\author{
Pandey $\mathrm{NK}^{1^{*}}$, Karki $\mathrm{P}^{1}$, Dhungana $\mathrm{S}^{1}$, Sherpa $\mathrm{K}^{2}$ \\ ${ }^{1}$ Department of Internal Medicine (Division of Cardiology) B.P. Koirala Institute of Health Sciences, \\ Dharan, Nepal \\ ${ }^{2}$ Department of Internal Medicine, B.P. Koirala Institute of Health Sciences, Dharan, Nepal
}

\begin{abstract}
Background: Metabolic syndrome is one of the major public health issues of this century. During the last decade, it has been shown that the metabolic syndrome and its various components increase the risk of cardiovascular diseases. The aim of this study was to determine the prevalence of metabolic syndrome and its components in patients with acute coronary syndrome admitted at a tertiary care center in Nepal.
\end{abstract}

Methods: This was a hospital based study in which consecutive 323 patients with acute coronary syndrome (ACS) were reviewed and the presence or absence of the metabolic syndrome and its components determined by applying modified NCEP-ATPIII criteria. Data was analyzed by using the Student $t$ test and Chi-square test.

Results: Among 323 patients with ACS, 219 (67.8\%) were males and 104 (32.19\%) were females. Out of them $193(59.7 \%)$ patients fulfilled criteria of metabolic syndrome and rest 130 (40.3\%) did not. All of the components of metabolic syndrome were significantly more in ACS patients with metabolic syndrome than in patients without metabolic syndrome $(p<0.001)$. The commonest component in ACS patients with or without metabolic syndrome was impaired blood sugar.

Conclusion: In ACS patients' metabolic syndrome is highly prevalent. Impaired blood sugar, reduced HDLc and hypertension were the most frequent metabolic components in ACS patients with metabolic syndrome. These findings show that drug therapy alone may not be fully effective unless risk factors causing metabolic syndrome are also addressed.

Keywords- metabolic syndrome, cardiovascular diseases, blood sugar and hypertension

\section{INTRODUCTION}

The metabolic syndrome is one of the major public health issues of this century. It increases an individual's risk for development of type 2 diabetes mellitus and coronary heart disease.

The South Asian countries like Nepal, India, Pakistan, Bangladesh and Srilanka account for a quarter of the world's population and contribute to the highest proportion of cardiovascular disease. ${ }^{1,2}$ If the current trend

*Corresponding author:

Email:nav dey31@yahoo.com

http://dx.doi.org/10.20530/IJTA 33 60-65

ISSN 2320-138X @ 2016 continues, the premature deaths and disabilities resulting from above conditions will increase the financial burden in developing countries. So, early identification and control of risk factors is the hallmark of success in reducing the incidence of coronary artery disease and thereby, reducing the economic burden.

Each component of metabolic syndrome is individually associated with an increased risk of cardiovascular disease; however, whether metabolic syndrome leads to greater cardiovascular risk than the sum of its components is a matter of debate. ${ }^{3}$ It has been suggested that the number of metabolic syndrome components may be more useful in predicting cardiovascular disease than 
Table 1: Clinical characteristics of male and female patients of ACS

\begin{tabular}{|c|c|c|c|}
\hline Variables & $\begin{array}{l}\text { Males } \\
\text { (219) }\end{array}$ & $\begin{array}{l}\text { Females } \\
(104)\end{array}$ & P value \\
\hline Age (years) & $59.3 \pm 11.2$ & $62.4 \pm 11.6$ & 0.012 \\
\hline Smoker, n (\%) & $164(75)$ & 20 (19) & $<0.001$ \\
\hline $\begin{array}{l}\text { Sedentary } \\
\text { lifestyle, n (\%) }\end{array}$ & $127(58)$ & $62(59.62$ & 0.782 \\
\hline $\begin{array}{l}\text { Alcohol } \\
\text { consumer, n } \\
(\%) \\
30 \mathrm{gm} / \mathrm{d}\end{array}$ & $50(22.8)$ & $4(3.8)$ & 0.0329 \\
\hline$W C(\mathrm{~cm})$ & $93 \pm 14.5$ & $88 \pm 15.5$ & 0.0049 \\
\hline FBS (mg/dl) & $136 \pm 56.5$ & $142 \pm 62$ & 0.328 \\
\hline HDLc (mg/dl) & $41 \pm 10.6$ & $44 \pm 12.5$ & 0.025 \\
\hline $\begin{array}{l}\text { Triglycerides } \\
\text { (mg/dl) }\end{array}$ & $149 \pm 74$ & $152.5 \pm 101.5$ & 0.726 \\
\hline SBP (mmHg) & $132 \pm 24$ & $138 \pm 28.5$ & 0.049 \\
\hline $\mathrm{DBP}(\mathrm{mmHg})$ & $84.5 \pm 14$ & $88.5 \pm 12.5$ & 0.01 \\
\hline \multicolumn{4}{|c|}{ Clinical Diagnosis } \\
\hline $\begin{array}{l}\text { Unstable } \\
\text { Angina, n (\%) }\end{array}$ & $55(25)$ & $45(43)$ & 0.001 \\
\hline NSTEMI, n (\%) & $29(13)$ & $23(22)$ & 0.038 \\
\hline STEMI, n (\%) & $135(62)$ & $36(35)$ & $<0.0001$ \\
\hline
\end{tabular}

ACS: acute coronary syndrome, WC: waist circumference, SBP: systolic blood pressure, DBP: diastolic blood pressure, HDLc: high density lipoprotein cholesterol, NSTEMI: Non ST segment elevation myocardial infarction, STEMI: STelevation myocardial infarction

metabolic syndrome itself, since cardiovascular risk increases as the number of components increases. ${ }^{4,5}$ Some studies have analyzed the prevalence of metabolic syndrome in patients with acute coronary disease, reporting an estimated prevalence of $41 \%-50 \%$ in Europe and the United States. ${ }^{4,6}$ The prevalence of metabolic syndrome in the general population of Dharan which lies in the eastern region of Nepal was $20.7 \%$ according to the NCEP criteria. ${ }^{7}$ But no such study has been done to know the prevalence of metabolic syndrome and the distribution of its component in patients with acute coronary syndrome in Nepal.

The present study aims to determine the prevalence of metabolic syndrome and its components in patients with acute coronary syndrome coming to B. P. Koirala Institute of Health Sciences (Nepal) which is a only tertiary care centre in the eastern region of Nepal.

\section{MATERIALS AND METHODS}

This hospital based study was conducted in the Department of Internal Medicine in collaboration with Department of Biochemistry at B. P. Koirala Institute of Health Sciences, Dharan, Nepal. In this study total of 323 consecutive patients more than 18 years with the diagnosis of acute coronary syndrome (ACS) defined according to the international guidelines for clinical practice ${ }^{8,9}$ were enrolled after approval from the Institutional Ethical Research committee. Each participant was provided with full information about the study, consent was taken and was assured of strict confidentiality. Patients with ACS and ascites or other comorbid illness like valvular heart disease, cardiomyopathies, renal failure, and chronic liver disease were excluded from the study.

Standardized complete demographic and clinical history was taken from every patient with emphasis on hypertension, type 2 Diabetes Mellitus, a sedentary lifestyle (defined as performing less than $30 \mathrm{~min}$ of moderate excercise 3 days per week), smoking, alcohol consumption, first degree relatives with coronary artery disease. Individuals were classified as being nonsmokers, current smokers, and former smokers (patients who had quit smoking at least 3 months before admission). Blood samples were collected at the time presentation for routine investigations and cardiac biomarkers. At least after 12 hours of fasting and within 24 hrs of presentation blood sample was again collected for measurement of plasma glucose and lipid profile by automated analyzer. Waist circumference was measured at midway between iliac crest and lower rib margin at the end of normal expiration using a plastic flexible tape to the nearest $0.1 \mathrm{~cm}$. Blood 
pressure was an average of at least two values taken in the right upper arm.

Patients were diagnosed as having metabolic syndrome by using modified NCEP-ATPIII ${ }^{10}$ criteria based on the presence of 3 or more of the following factors: a) Central obesity: Waist circumference $\geq 90 \mathrm{~cm}$ for male and $\geq 80 \mathrm{~cm}$ for female; b) hypertriglyceridemia, defined as fasting plasma triglycerides $>150 \mathrm{mg} / \mathrm{dL}$ previous to or within $24 \mathrm{hr}$ of admission or on specific medication; c) hypertension, defined as blood pressure $\geq 130 \mathrm{mmHg}$ systolic or $\geq 85$ $\mathrm{mmHg}$ diastolic, or on specific medication; d) low plasma HDLc, defined as $<40 \mathrm{mg} / \mathrm{dL}$ for men and $<50 \mathrm{mg} / \mathrm{dL}$ for women, measured either before or within the first $24 \mathrm{hrs}$ of admission, or on specific medication; and d) fasting plasma glucose $\geq 100 \mathrm{mg} / \mathrm{dL}$ or on specific medication or previously diagnosed type 2 diabetes. between qualitative variables. $\mathrm{P}$ value of $<.05$ was used as a cutoff for statistical significance.

\section{RESULTS}

Out of the study population, $68 \%$ were male and $32 \%$ were female. Their clinical characteristics are shown in Table 1 . Women with ACS were comparatively older than men but there was no significant difference in sedentary life style between men and women. Men with ACS had significantly increased smoking (current and former) history than female. Likewise men had significantly increased amount of alcohol consumption than female. Among these patients, 59.7\% (193) had the metabolic syndrome according to the modified NCEP ATPIII criteria. The metabolic syndrome was significantly more common in women than in men $(76.92 \%$ vs. $51.59 \%, p<0.001$ ) (Fig. 1)

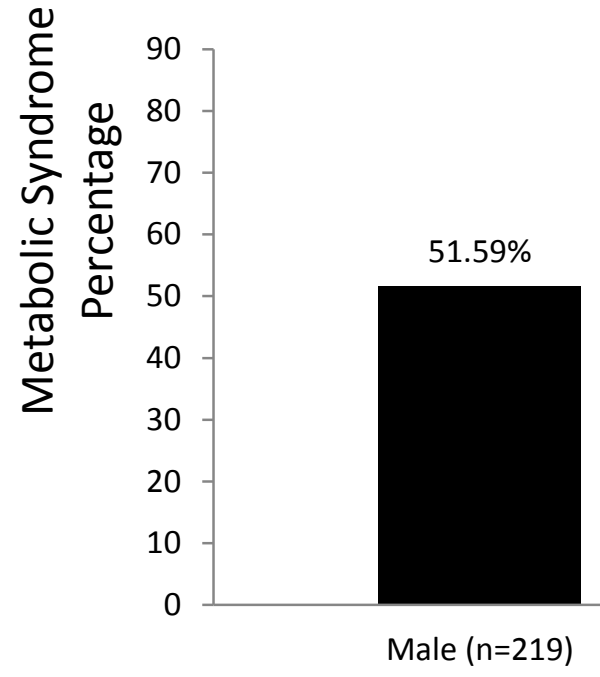

$p=<0.001$

\section{$76.92 \%$}

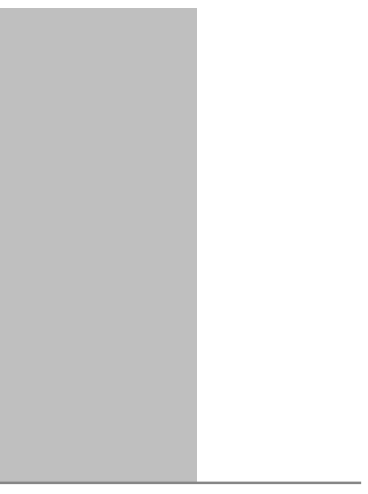

Female $(n=104)$

Fig. 1: Metabolic syndrome in male and female patients of ACS

\section{STATISTICAL ANALYSIS}

Data was entered in microsoft Excel Work sheet and analyzed using SPSS version 11.5. Quantitave variables are expressed as mean \pm standard deviation, and qualitative variables are presented in frequencies and percentages. Normally distributed data was analyzed using the Student t-test to compare means; otherwise the Mann-Whitney $U$ test was used. The $\mathrm{X}^{2}$ will be used to analyze differences
The most frequent metabolic component in male was impaired blood sugar followed by waist circumference and then hypertension but there was no significant difference in number of male having impaired blood sugar compared to female. In female the most common component was waist circumference which was significantly in more number of female than male. The second common 
component of metabolic syndrome in female was low HDLc which was significantly lower in more female than in male. There was no difference in percentage of male and female with ACS having high triglyceride level.( Table 2 )

In 130 (40.3\%) patients criteria for metabolic syndrome was not fulfilled. All of the components of metabolic syndrome was significantly more in number in patients with metabolic syndrome than in patients without metabolic syndrome as shown in Fig 2.In patients with metabolic syndrome the most common component was impaired blood sugar (84\%) which was also the main component in patients without metabolic syndrome (47\%). The second most common component in patients with metabolic syndrome was low HDLc followed by hypertension while in patients without metabolic syndrome it was hypertension (38.2\%) followed by low HDLc (35\%).

Table 2: Metabolic syndrome components in male and female patients with ACS

\begin{tabular}{llll}
\hline Component & $\begin{array}{l}\text { Male } \\
(\mathbf{2 1 9 )}\end{array}$ & $\begin{array}{l}\text { Female } \\
(\mathbf{1 0 4})\end{array}$ & $\begin{array}{l}\boldsymbol{P} \\
\text { value }\end{array}$ \\
\hline IBS n (\%) & 142 & 67 & 0.966 \\
& $(64.84)$ & $(64.6)$ & \\
\hline Low HDLc n (\%) & 123 & 77 & 0.002 \\
& $(56.16)$ & $(74.03)$ & \\
\hline Hypertension n (\%) & 123 & 71 & 0.038 \\
& $(56.16)$ & $(68.26)$ & \\
\hline Hypertriglyceridemia & $92(42)$ & 45 & 0.83 \\
n (\%) & & $(43.26)$ & \\
$\begin{array}{l}\text { Waist circumference } \\
\text { n (\%) }\end{array}$ & 134 & 84 & $<0.004$ \\
\hline
\end{tabular}

IBS: Impaired blood sugar, HDLc: High density lipoprotein cholesterol

\section{DISCUSSION}

In this study we found that prevalence patients with ACS had a high prevalance of metabolic syndrome (59.7\%). This percentage is more or less similar to that described in other studies done in India in which prevalence was $59 \%{ }^{11}$ but it used IDF criteria and in Pakistan prevalence was reported as $40.7 \%$. $^{12}$
A randomly selected population of six clusters in the city of Jaipur, India, found the prevalence of the metabolic syndrome as being $7.9 \%$ in males and $17.5 \%$ in females. ${ }^{13}$ In a study done in local poulation of Dharan, Nepal prevalence of metabolic syndrome was found to be $20.7 \%{ }^{7}$

This shows that the prevalence of metabolic syndrome is higher in populations with acute coronary syndrome than in the general population. This demonstrates the association between ischemic heart disease and metabolic syndrome. In a study it has been shown that MS is an independent predictor of ACS in patients in secondary prevention. ${ }^{14}$ In this sense, the present study shows that metabolic syndrome tends to be more prevalent in patients with atherosclerotic vascular disease.

In this study prevalence of metabolic syndrome in female with ACS was more than in patients with male (76.92\% vs51.59\%), which is similar to the results obtained in other populations with ischemic heart disease. $^{15,16}$

Metabolic syndrome increases cardiovascular risk and each of its components is associated with an increased risk of cardiovascular disease. Now interest is growing in the components of metabolic syndrome, not only in relation to the number present but also their different combinations, for predicting cardiovascular risk. This study showed hyperglycemia as the most common component of MS than low HDLc followed by hypertension. In a study ${ }^{17}$, this was also the most frequent combination. This shows the importance of public screening programs for early detection of risk factors for ACS.

Physical activity increases insulin sensitivity and HDLc, lowers BP and reduces risk of Type $2 \mathrm{DM}$ and central obesity. ${ }^{18-20}$ In our study the most common component of MS in female was increased waist circumference followed by low HDLc. This may be because of decreased physical activity, unhealthy eating habits or may be related to genetics which needs further larger study to be verified. 


\section{CONCLUSION}

Metabolic syndrome has become a global and major public health problem. In ACS patient's metabolic syndrome is highly prevalent. A concerted and coordinated efforts by the government and the clinicians is required to recognize MS or its components early in individuals and to implement prophylactic lifestyle and pharmacological interventions at the individual and population level which will decrease the incidence of MS and thereby combat the high incidence of coronary heart disease.

\section{REFERENCES}

1. Yusuf S, Reddy S, Ounpuu S, Anand S. Global Burden of Cardiovascular Diseases: Part I: General Considerations, the Epidemiologic Transition, Risk Factors, and Impact of Urbanization. Circulation; 2001 Nov 27;104(22):2746-53. Available from: http://dx.doi.org/10.1161/hc4601.099487

2. Reddy KS. Cardiovascular Disease in NonWestern Countries. N Engl J Med; 2004 Jun 10;350(24):2438-40. Available from: http://dx.doi.org/10.1056/nejmp048024

3. Mente A, Yusuf S, Islam S, McQueen MJ, Tanomsup S, Onen CL, et al. Metabolic Syndrome and Risk of Acute Myocardial Infarction. Journal of the American College of Cardiology; 2010 May; 55(21):2390-8. Available from: http://dx.doi.org/10.1016/j.jacc.2009.12.053

4. Solymoss BC, Bourassa MG, Campeau L, Sniderman A, Marcil $M$, Lespérance J, et al. Effect of increasing metabolic syndrome score on atherosclerotic risk profile and coronary artery disease angiographic severity. The American Journal of Cardiology; 2004 Jan;93(2):159-64. Available from: http://dx.doi.org/10.1016/j.amjcard.2003.09. $\underline{032}$

5.Lakka H-M. The Metabolic Syndrome and Total and Cardiovascular Disease Mortality in Middle-aged Men. JAMA; 2002 Dec 4;288(21):2709. Available from: http://dx.doi.org/10.1001/jama.288.21.2709

6. Chung EH, Curran PJ, Sivasankaran S, Chauhan MS, Gossman DE, Pyne CT, et al.
Prevalence of Metabolic Syndrome in Patients $\leq 45$ Years of Age With Acute Myocardial Infarction Having Percutaneous Coronary Intervention. The American Journal of Cardiology ; 2007 Oct;100(7):1052-5. Available from: http://dx.doi.org/10.1016/i.amjcard.2007.05. $\underline{028}$

7.Sharma SK, Ghimire A, Radhakrishnan J, Thapa L, Shrestha NR, Paudel N, et al. Prevalence of Hypertension, Obesity, Diabetes, and Metabolic Syndrome in Nepal. International Journal of Hypertension; 2011;2011:1-9. Available from: http://dx.doi.org/10.4061/2011/821971

8.Myocardial infarction redefined-A consensus document of The Joint European Society of Cardiology/American College of Cardiology Committee for the Redefinition of Myocardial Infarction. European Heart Journal; 2000 Sep 15;21(18):1502-13. Available from: http://dx.doi.org/10.1053/euhj.2000.2305

9.Braunwald E. ACC/AHA Guideline Update for the Management of Patients With Unstable Angina and Non-ST-Segment Elevation Myocardial Infarction--2002: Summary Article: A Report of the American College of Cardiology/American Heart Association Task Force on Practice Guidelines (Committee on the Management of Patients With Unstable Angina). Circulation; 2002 Oct 1;106(14):1893-900. Available from: http://dx.doi.org/10.1161/01.cir.0000037106. $\underline{76139.53}$

10.Grundy SM, Cleeman JI, Daniels SR, Donato $K A$, Eckel RH, Franklin BA, et al. Diagnosis and management of the metabolic syndrome. Current Opinion in Cardiology; 2006 Jan;21(1):1-6. Available from: http://dx.doi.org/10.1097/01.hco.000020041 $\underline{6.65370 . a 0}$

11. Dhakhada V, Panjwani M, Dabhi A. Study of Association Between Metabolic Syndrome and Acute Coronary Syndrome.Indian Journal of Clinical Practice. 2013;24(4):324-327

12.Kabir $M$, Hossain $M$, Haque $M$, Fakir $M$, Rahimgir $M$, Momtaz $S$. Prevalence of Metabolic Syndrome in Army Personnel Residing in Bogra Cantonment. Journal of 
Armed Forces Medical College, Bangladesh; 2013 Sep 7;8(2). Available from: http://dx.doi.org/10.3329/jafmc.v8i2.16354

13.Gupta A, Gupta R, Sarna M, Rastogi S, Gupta VP, Kothari K. Prevalence of diabetes, impaired fasting glucose and insulin resistance syndrome in an urban Indian population. Diabetes Research and Clinical Practice;61(1):69-76. Available from: http://dx.doi.org/10.1016/s0168-

8227(03)00085-8

14. Nakatani $D$, Sakata $Y$, Sato $H$, Mizuno $H$, Shimizu M, Suna $S$, et al. Clinical Impact of Metabolic Syndrome and Its Additive Effect With Smoking on Subsequent Cardiac Events After Acute Myocardial Infarction. The American Journal of Cardiology; 2007 Apr;99(7):885-9. Available from: http://dx.doi.org/10.1016/j.amjcard.2006.11. $\underline{033}$

15. Milani RV, Lavie CJ. Prevalence and profile of metabolic syndrome in patients following acute coronary events and effects of therapeutic lifestyle change with cardiac rehabilitation. The American Journal of Cardiology; 2003 Jul;92(1):50-4. Available from: $\quad$ http://dx.doi.org/10.1016/s00029149(03)00464-8

16.R. Zaliunas, M.R. Babarskiene, D. Luksiene, B. Slapikiene, J. Vencloviene, I. Milvidaite, et al. The risk of cardiovascular death following the first acute ischaemic syndrome: experience in Kaunas between 1997 and 2001. Acta Cardiologica ;62(4):329-37. Available from:

http://dx.doi.org/10.2143/ac.62.4.2022275

17.Kim J-Y, Mun H-S, Lee BK, Yoon SB, Choi E$Y$, Min P-K, et al. Impact of Metabolic Syndrome and Its Individual Components on the Presence and Severity of Angiographic Coronary Artery Disease. Yonsei Med J;51(5):676. Available from: http://dx.doi.org/10.3349/ymj.2010.51.5.67

18. Rastogi T. Physical activity and risk of coronary heart disease in India. International Journal of Epidemiology; 2004 Jul 28;33(4):759-67. Available from: http://dx.doi.org/10.1093/ije/dyh042

19.Wannamethee SG, Shaper AG, Alberti KGMM. Physical Activity, Metabolic Factors, and the Incidence of Coronary Heart Disease and Type 2 Diabetes. Archives of Internal Medicine; 2000 Jul 24;160(14):2108. Available from:

http://dx.doi.org/10.1001/archinte.160.14.21 $\underline{0}$

20.Physical Activity and Cardiovascular Health. JAMA; 1996 Jul 17;276(3):241. Available from: http://dx.doi.org/10.1001/jama.1996.035400 $\underline{30075036}$ 